\title{
Optimizing the effect of reinforcement, particle size and aging on impact strength for Al 6061-red mud composite using Taguchi technique
}

\author{
NARENDER PANWAR and AMIT CHAUHAN*D \\ Department of Mechanical Engineering, University Institute of Engineering and Technology, Panjab University, \\ Chandigarh 160014, India \\ e-mail: narender.16k@gmail.com; drchauhan98@gmail.com
}

MS received 5 May 2017; revised 9 February 2018; accepted 8 March 2018; published online 18 June 2018

\begin{abstract}
Aluminium 6061-red mud composite has been successfully casted by using stir casting. Fairly uniform distribution of red mud reinforcement has been observed by SEM micrographs. The presence of red mud particles inside the matrix has been confirmed by energy dispersive spectroscopy. Impact testing has been done on impact testing machine with a range of 1-300 J (Charpy), 1-175 (Izod) and least count of $0.5 \mathrm{~J}$. Impact strength shows a decreasing trend with increase in percentage reinforcement, aging time and is increased with increase in particle size. ANOVA analysis found that the effect of particle size and aging time are significant but the effect of percentage reinforcement has not been found significant. From the analysis, it can be observed that the particle size influences the impact strength most followed by aging time and percentage reinforcement. Optimum value of impact strength has been predicted by using Taguchi technique and confirmed experimentally by confirmation experiment results.
\end{abstract}

Keywords. Metal matrix composite; red-mud; aluminium 6061; impact strength; ANOVA.

\section{Introduction}

Aluminium and its alloys reinforced with hard ceramic particulates, called as aluminium matrix composites (AMCs). Normal aluminium alloys failed to meet the increasing demand for modern heavy performance applications. AMCs have improved properties like stiffness, strength, resistance to wear, higher strength-to-weight ratio, low coefficient of thermal expansion, tensile strength, fatigue strength, makes them preferable over aluminium alloys. Application of advanced composite materials in structural components is attractive due to their good stiffness/strength-to-weight ratios. Reinforcement type, fabrication method affects the properties of AMCs. AMCs emerged as one of the most useful materials for aeronautical, automobile, defence, and some other areas of application [1-10]. Mostly hard ceramic particles have been used as reinforcements and commonly used reinforcements in AMCs are $\mathrm{SiC}, \mathrm{TiB}_{2}, \mathrm{~B}_{4} \mathrm{C}, \mathrm{BN}$, AlN, $\mathrm{AL}_{2} \mathrm{O}_{3}, \mathrm{TiO}_{2}, \mathrm{CNT}, \mathrm{SiO}_{2}$,etc. Waste materials such as rice husk ash, fly ash, bamboo leaf ash, bagasse, etc. are also used as reinforcement in AMCs. Reinforcement materials used may be of a single material or a combination of two or more materials [11-15]. There have been

*For correspondence many fabrication methods for producing AMCs. The methods used for production of AMCs can be classified as solid state, liquid state, and gas state. Powder metallurgy and diffusion bonding has been most used solid state methods. Liquid state methods include, squeeze casting, compo casting, in situ, spray co-deposition, stir casting, etc. Gaseous state method used physical vapour deposition. Out of these available methods, stir casting has been most simple economical and flexible. In this method, particles of reinforcement have been added to matrix by mechanical stirring [16-22]. Design of experiment (DOE) techniques such as Taguchi, response surface methodology, etc. has gained importance in recent times for finding influence of parameters, their combined effects and order of significance of their effect [23]. Taguchi method uses orthogonal array for reducing counting of experimental runs for optimizing considered parameters and their interactions. In Taguchi technique, signal-to noise $(\mathrm{S} / \mathrm{N})$ ratio represents performance characteristic and highest $\mathrm{S} / \mathrm{N}$ ratio value has been considered. By considering objective of the experiment, anyone of the $\mathrm{S} / \mathrm{N}$ ratios, called lower-the-better, larger-the-better and nominal-the-better has been chosen for further analysis [24].

It has been observed from the literature that the impact strength of aluminum matrix composite has not been much 
investigated for ceramic reinforcements. Authors have also not found much on the effect of particle size on the impact strength of composite under study in literature. Therefore, the present study has been aimed to the investigation of effect of parameters on impact strength of Al 6061/red-mud composite. The composite has been fabricated by stir casting method. A statistical analysis of parameters affecting impact strength has been carried out using Taguchi technique. Analysis of variance (ANOVA) has been applied to find out contribution of effect of each parameter on impact strength of the developed composite.

\section{Experimental procedure}

\subsection{Material preparation}

Aluminium 6061 has been selected as matrix material. Red-mud a waste produced during extraction of aluminium from bauxite by Buyer's process has been taken as reinforcement material and is procured from HINDALCO, Renukut, Utter Pradesh, India. XRF analysis of red mud used for experimentation has been given in table 1 .

Table 1. XRF result of red mud used in this study

\begin{tabular}{|c|c|c|}
\hline Sr. no. & Constituent & Percentage \\
\hline 1 & $\mathrm{Fe}_{2} \mathrm{O}_{3}$ & 35.26 \\
\hline 2 & $\mathrm{Al}_{2} \mathrm{O}_{3}$ & 21.89 \\
\hline 3 & $\mathrm{TiO}_{2}$ & 15.11 \\
\hline 4 & $\mathrm{SiO}_{2}$ & 12.46 \\
\hline 5 & $\mathrm{Na}_{2} \mathrm{O}$ & 11.82 \\
\hline 6 & $\mathrm{CaO}$ & 1.83 \\
\hline 7 & $\mathrm{P}_{2} \mathrm{O}_{5}$ & 0.40 \\
\hline 8 & $\mathrm{~V}_{2} \mathrm{O}_{5}$ & 0.38 \\
\hline 9 & $\mathrm{SO}_{2}$ & 0.19 \\
\hline 10 & $\mathrm{ZrO}_{2}$ & 0.15 \\
\hline 11 & $\mathrm{~K}_{2} \mathrm{O}$ & 0.13 \\
\hline 12 & $\mathrm{MgO}$ & 0.12 \\
\hline 13 & $\mathrm{Cr}_{2} \mathrm{O}_{3}$ & 0.11 \\
\hline 14 & $\mathrm{Cl}$ & 0.04 \\
\hline 15 & $\mathrm{MnO}$ & 0.04 \\
\hline 16 & $\mathrm{CuO}$ & 0.02 \\
\hline 17 & $\mathrm{Sc}_{2} \mathrm{O}_{3}$ & 0.01 \\
\hline 18 & $\mathrm{Ga}_{2} \mathrm{O}_{3}$ & 0.01 \\
\hline 19 & $\mathrm{Nb}_{2} \mathrm{O}_{5}$ & 0.01 \\
\hline 20 & $\mathrm{ZnO}$ & $65 \mathrm{PPM}$ \\
\hline 21 & $\mathrm{Ag}$ & $56 \mathrm{PPM}$ \\
\hline 22 & $\mathrm{PbO}$ & 47PPM \\
\hline 23 & $\mathrm{As}_{2} \mathrm{O}_{3}$ & 45PPM \\
\hline 24 & $\mathrm{NiO}$ & 44PPM \\
\hline 25 & $\mathrm{SrO}$ & 43PPM \\
\hline 26 & $\mathrm{Y}_{2} \mathrm{O}_{3}$ & 22PPM \\
\hline
\end{tabular}

Experiments have been planned using Taguchi design of experiments. According to chosen variable parameters and their variation levels L25 Orthogonal Array (OA) has been selected for experimentation. The variable parameters with their variation levels have been given in table 2 .

\subsection{Fabrication of composite}

The composite under study has been fabricated by stir casting. Aluminium 6061 has been melted inside graphite crucible to a temperature of $800^{\circ} \mathrm{C}$ using muffle furnace. Vortex of molten metal has been obtained by stirring. Stirring has been done by mechanical stirrer (figure 1) at 400 RPM. Figure 1 explains the design of mechanical stirrer used for mixing of reinforcement during the fabrication process.

Reinforcement pre-heated at $400^{\circ} \mathrm{C}$ has been poured to vortex ensuring homogeneous distribution of red-mud. Magnesium has been added to improve the wettability of red-mud particles with molten aluminium 6061. Magnesium has been added in the form of magnesium turning by wrapping it into aluminum foil before the addition of red-mud particles. The melt has been poured into preheated metallic moulds. Solutionizing of fabricated composite has been done for homogenizing the structure and properties. In this process, the composite has been heated at $525^{\circ} \mathrm{C}$ for eight hours in a furnace. After heating, the composite has been quenched in water. Aging of the prepared samples has been done in electric muffle furnace. Aging temperature of the samples has been $175 \pm 5^{\circ} \mathrm{C}$. The SEM images of casted, homogenised and aged samples have been shown in figure $2 \mathrm{a}-$ c. It can be observed from the figures that homogenizing and aging improves surface of composite and reduce cracks.

Aging time durations taken are: $0.5,6,12,18$ and $24 \mathrm{~h}$. Energy dispersive spectroscopy (EDS) of fabricated samples confirms the presence of constituents of red mud inside the aluminium 6061 matrix. Spectrum of EDS has been presented in figure 3 and is given below.

Table 2. Selected parameters and corresponding levels

\begin{tabular}{llccccc}
\hline $\begin{array}{l}\text { Sr. } \\
\text { no. }\end{array}$ & Parameters & $\begin{array}{c}\text { Level- } \\
1\end{array}$ & $\begin{array}{c}\text { Level- } \\
2\end{array}$ & $\begin{array}{c}\text { Level- } \\
3\end{array}$ & $\begin{array}{c}\text { Level- } \\
4\end{array}$ & $\begin{array}{c}\text { Level- } \\
5\end{array}$ \\
\hline 1 & $\begin{array}{c}\text { Percentage } \\
\text { reinforcement } \\
(\text { by wt) }\end{array}$ & 4 & 8 & 12 & 16 & 20 \\
2 & $\begin{array}{c}\text { Particle size } \\
(\mu \mathrm{m})\end{array}$ & 250 & 177 & 149 & 125 & 74 \\
3 & Ageing time (h) & $1 / 2 \mathrm{~h}$ & 6 & 12 & 18 & 24 \\
\hline
\end{tabular}




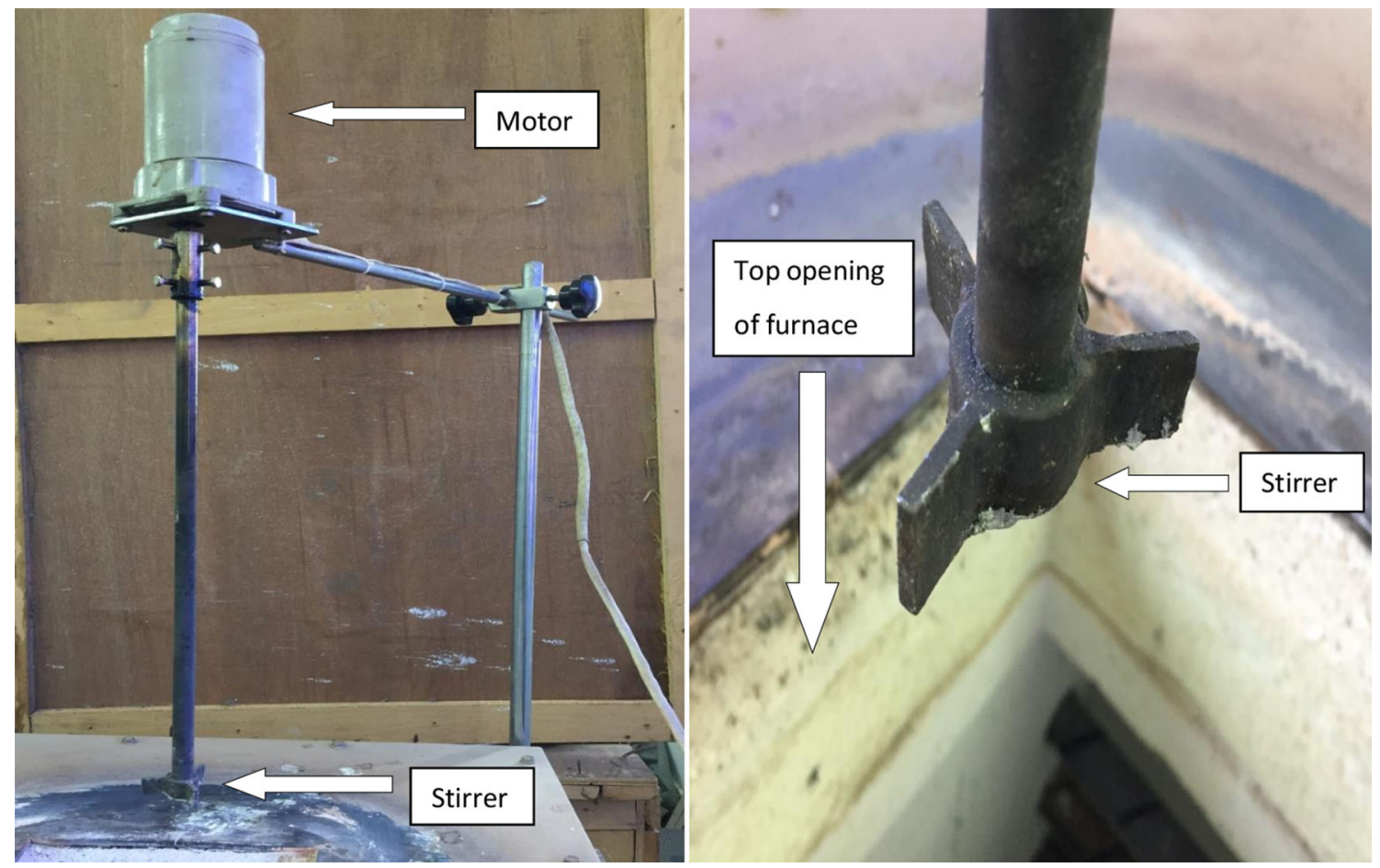

Figure 1. Stirrer used for casting of aluminium 6061 red-mud composite and stirrer blades.

\subsection{Impact test}

Impact testing has been done on impact testing machine with a range of 1-300 J (Charpy), 1-175 (Izod) and least count of $0.5 \mathrm{~J}$. Testing has been carried out at atmospheric condition of $25 \pm 3^{\circ} \mathrm{C}$ temperature and relative humidity of $40-60 \%$. A repetition of two has been done for each kind to reduce errors.

\subsection{Scanning electron microscopy (SEM)}

SEM images of fabricated composites have been taken after casting and after impact test. Casted samples have been machined and polished before SEM. Surface of SEM samples prepared by rubbing with emery papers of grit sizes $60,150,220,400,600,1000$, and after that it is polished with high concentration diamond paste with $1 \mu \mathrm{m}$ particle size on polishing cloth. SEM images of fractured surface after impact test has also been taken at different magnifications shown in each image. Sample thickness of $5 \mathrm{~mm}$ has been taken for each sample.

\section{Results and discussion}

\subsection{Microstructure}

From SEM images for the samples after casting shown in figure $4 \mathrm{a}-\mathrm{e}$, clearly visible particles inside the aluminium
6061 matrix are seen. It has also been observed from the images that the distribution of particles inside the matrix is fairly uniform.

SEM images in figure 5 reveal that fracture is of brittle nature in the region of reinforcement and is of ductile in rest of matrix phase. Figure 5a and d show the low magnification image of impact fracture and observed that cracks are propagated near the red-mud particles. The $100 \times$ magnification images (figure $5 \mathrm{~b}$ and e) show the red-mud particles on the fractured surface. Higher magnification images of fractured surface at $200 \times$ i.e., figure $5 \mathrm{c}$ and $\mathrm{f}$ indicate that fracture is partially ductile and partially brittle in nature. The granuallar surface indicates brittle nature of fracture and the rought surface indicates ductile nature of the fracture. It has also been observed from figure $5 \mathrm{c}$ and $\mathrm{f}$ that higher particle size (figure 5f) shows more ductile nature than the smaller particle size (figure 5c) and the same is also reflected from table 3 experiment number 21 (impact strength = $8.50 \mathrm{~J}$ ) has more impact strength than experiment number 18 (impact strength $=8.00 \mathrm{~J}$ ).

\subsection{Impact strength}

Effects of variables on impact strength have been studied at five levels. Orthogonal array $\mathrm{L}_{25}$ has been selected for conducting the experiments. Total number of fifty experiments have been conducted with a repetition of twice. The 


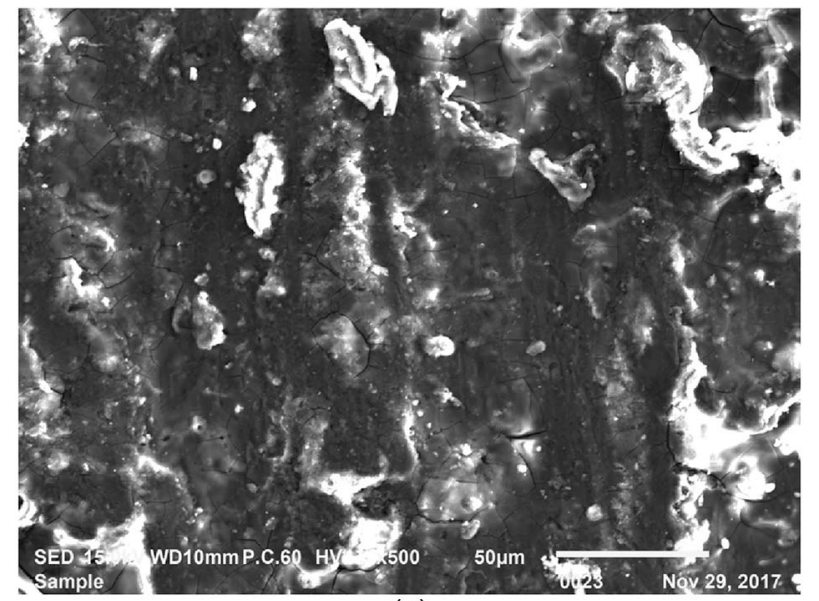

(a)

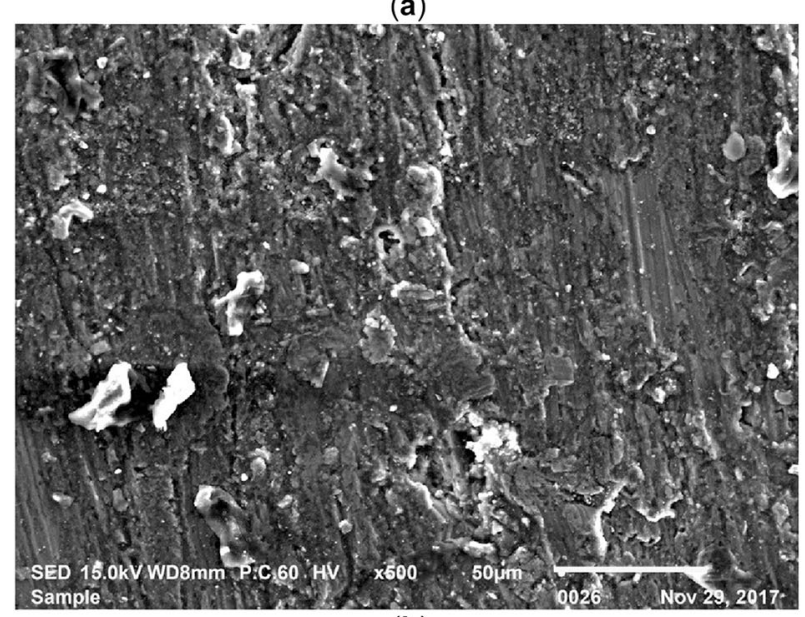

(b)

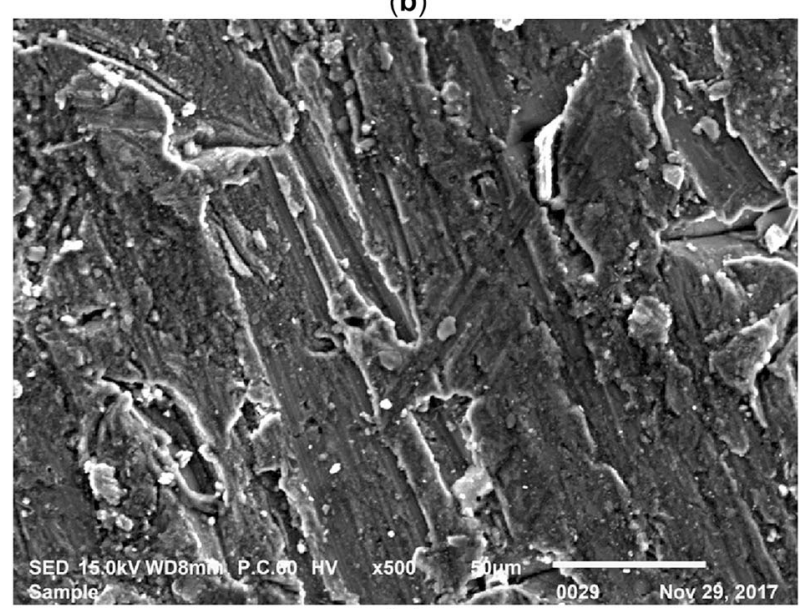

(c)

Figure 2. SEM image of fabricated samples in conditions: as cast, homogenized and after aging. (a) SEM image of casting without heat treatment. (b) SEM image of homogenized heat treated sample. (c) SEM image of sample after aging.

experimentally obtained results have been reported in table 3 . There are three types of quality characteristics in Taguchi method which are as follows: smaller is better, nominal is
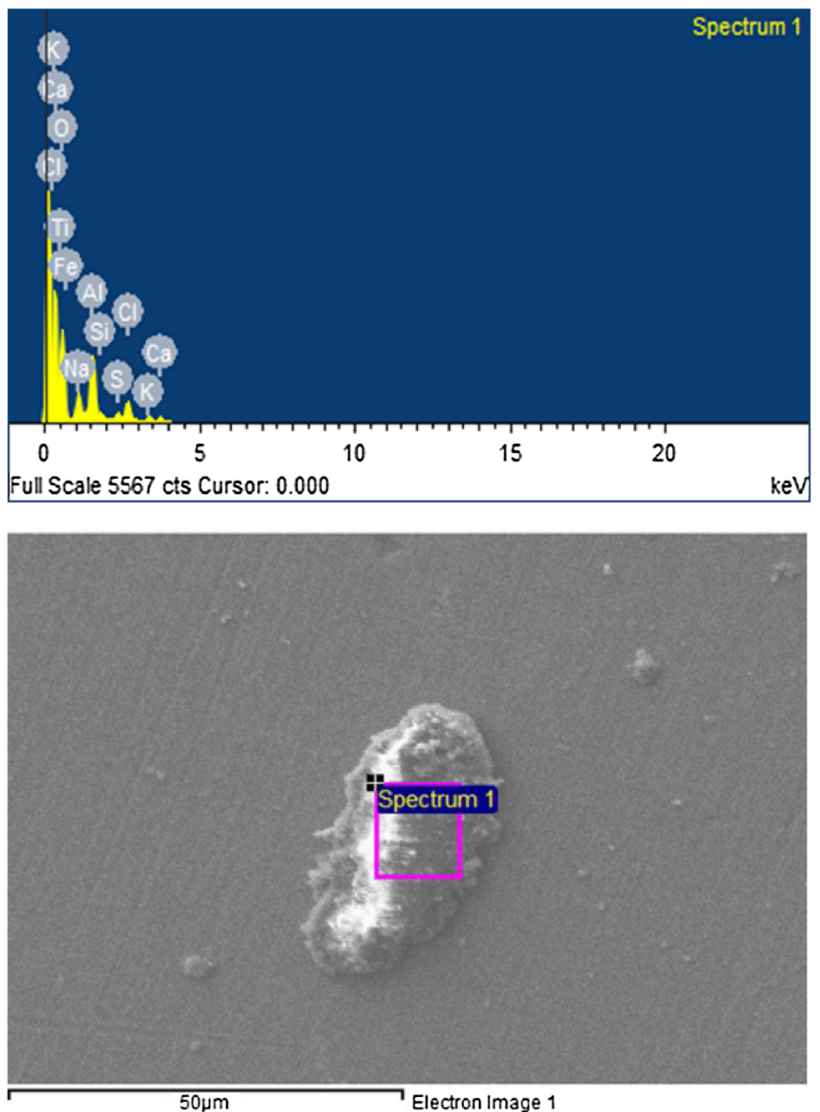

Figure 3. EDS spectra taken from red-mud particle.

better and larger is better. Larger is better quality characteristics have been used as higher impact strength is desired.

Tables 4 and 5 report the mean values of $\mathrm{S} / \mathrm{N}$ ratios and mean of mean for impact strength of the fabricated composite at each level. The deference between the highest and lowest value for each variable has been called delta value. The delta analysis observed that the particle size affects the impact strength most (rank 1) followed by aging time (rank 2 ) and percentage reinforcement (rank 3). The plot of mean values of impact strength at each level has also been shown in figure 6.

3.2a ANOVA analysis: Analysis of variance (ANOVA) of Impact strength has been done using Minitab 17 software. In this analysis sum of squares, variance, F-ratio and $P$ value has been calculated as shown in following table 6. Percentage contribution of effect of percentage reinforcement on impact strength is least $(2.29 \%)$, for aging time it is $(10.77 \%)$ and for particle size $(79.12 \%)$ is highest. For a parameter to called significant $\mathrm{P}$ value should be less than 0.05 . According to $P$ value effect of particle size and aging time has been found to be significant while the effect of percentage reinforcement has not found to be significant. 
(a)
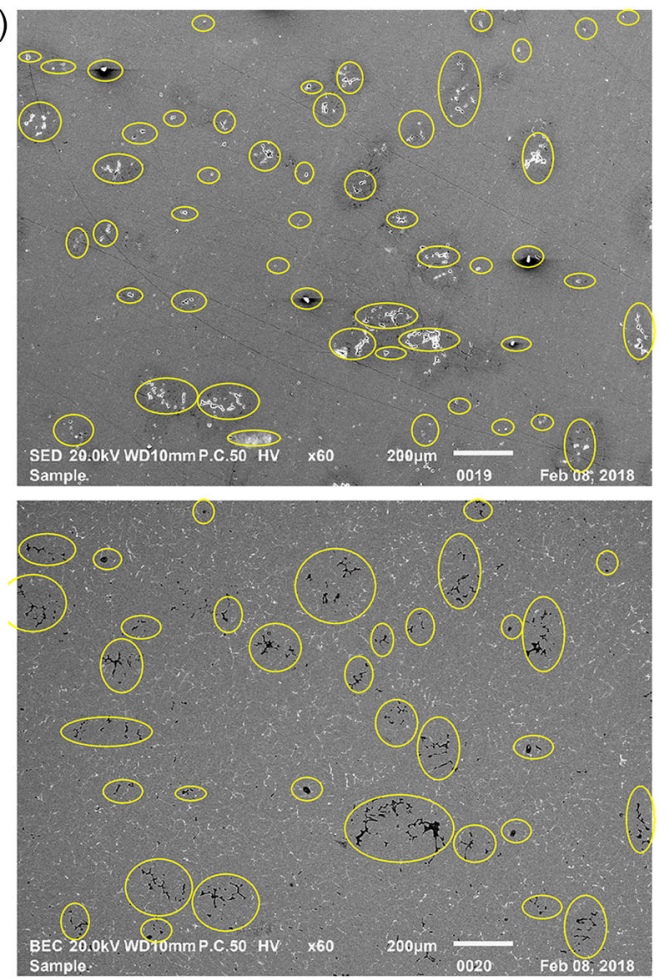

(c)
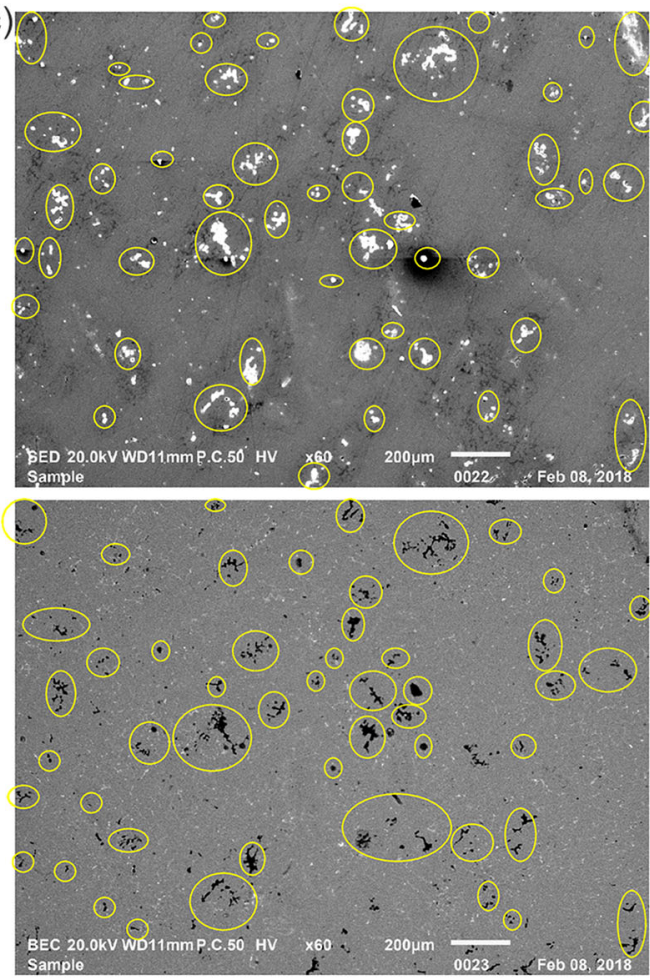

(b)
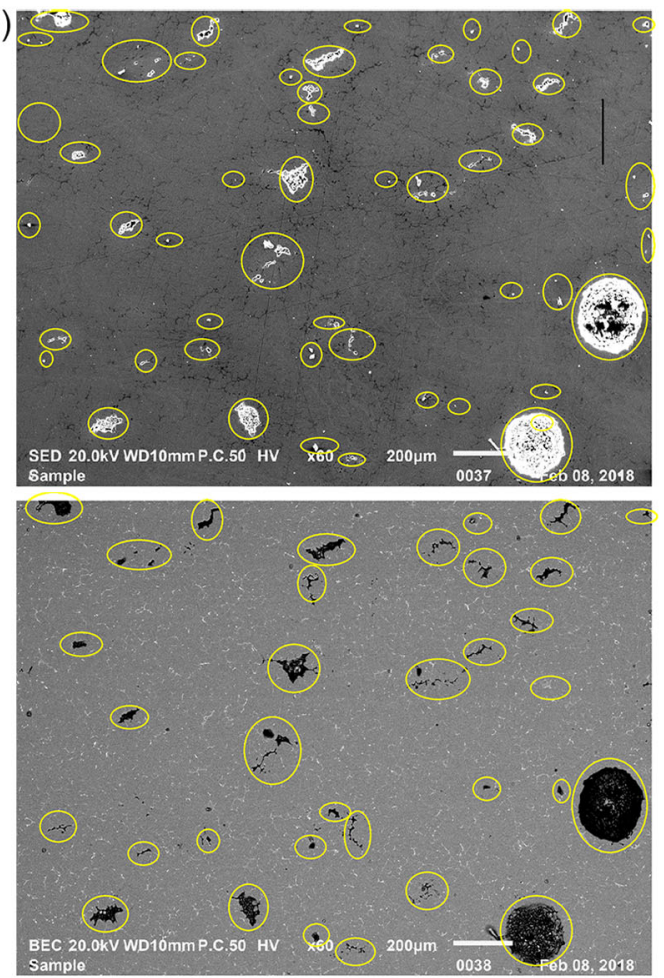

(d)
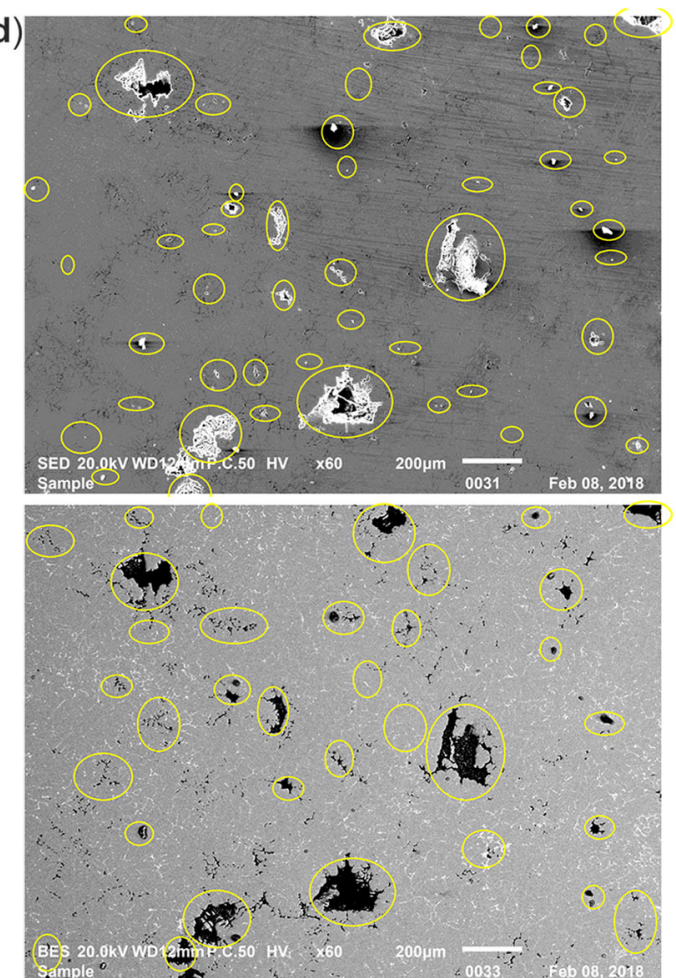

Figure 4. (a) Secondary electron (SEC) and backscattered (BEC) image of casted samples of aluminium red-mud composite at $4 \%$ redmud: (i) red-mud 4\% SED. (ii) red-mud 4\% BEC. (b) Secondary electron (SEC) and backscattered (BEC) image of casted samples of aluminium red-mud composite at $8 \%$ red-mud: (i) red-mud $8 \%$ SED. (ii) red-mud $8 \%$ BEC. (c) Secondary electron (SEC) and backscattered (BEC) image of casted samples of aluminium red-mud composite at $12 \%$ red-mud: (i) red-mud $12 \%$ SED. (ii) red-mud $12 \%$ BEC. (d) Secondary electron (SEC) and backscattered (BEC) image of casted samples of aluminium red-mud composite at 16\% red-mud: (i) red-mud 16\% SED. (ii) red-mud 16\% BEC. (e) Secondary electron (SEC) and backscattered (BEC) image of casted samples of aluminium red-mud composite at 20\% red-mud: (i) red-mud 20\% SED. (ii) red-mud 20\% BEC. 
(e)
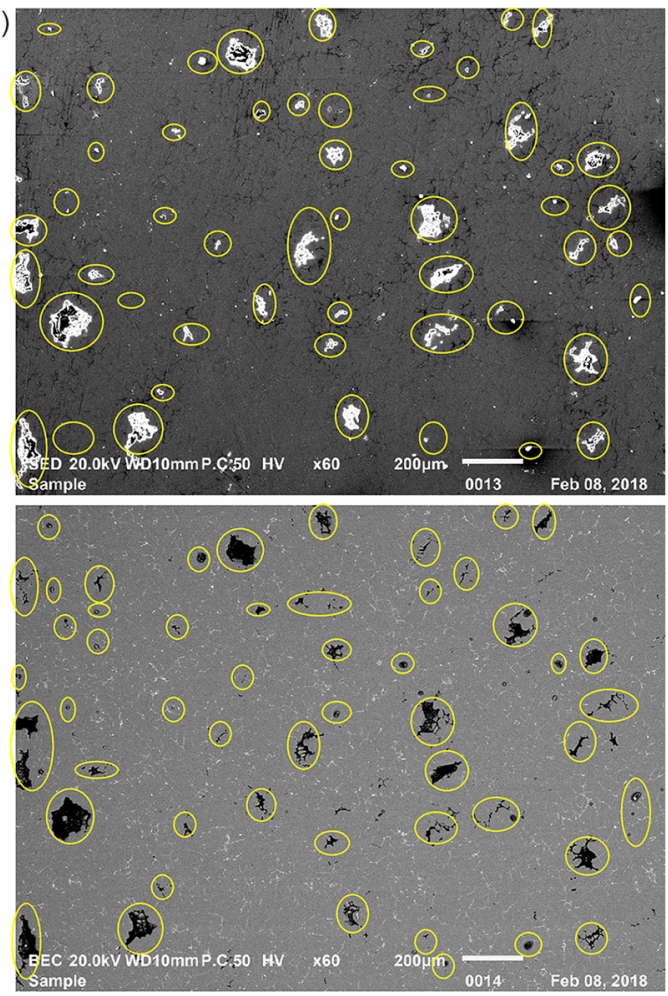

Figure 4. continued

The delta analysis of mean values of experimental results in table 5 also found the same results as obtained by ANOVA analysis i.e., particle size (79.12\%, rank-1) has been most influencing parameter followed by aging time $(10.77 \%$, rank-2) and percentage reinforcement of red-mud $(2.29 \%$, rank-3).

3.2b Estimation of optimum impact strength: Under this part, optimum value of impact strength and its confidence interval is predicted theoretically using Taguchi's approach. By recognising the effect of factors, the optimum value of impact strength has been predicted. The significant process parameters for impact strength are $B_{5}$ and $C_{1}$. The mean value of calculated impact strength is [25]:

$$
\mu_{\mathrm{J}}=\mathrm{B}_{5}+\mathrm{C}_{1}-\mathrm{T}_{\mathrm{J}}
$$

where $T_{J}$ is average of all values of impact strength $7.40 \mathrm{~J} ; \mathrm{B}_{5}$ average value of impact strength at fifth level of particle size $=10.60 \mathrm{~J} ; \mathrm{C}_{1}$ average value of impact strength at first level of aging time: $8.60 \mathrm{~J}$; $\mu_{\mathrm{J}}=11.8 \mathrm{~J}$

Predicted value of confidence interval

$$
\mathrm{CI}=\sqrt{F_{\alpha}\left(1, f_{e}\right) V_{e}\left[\frac{1}{n_{e f f}}+\frac{1}{R}\right]}
$$

where $\mathrm{CI}$, confidence interval; $\mathrm{F}_{\alpha}\left(1, \mathrm{f}_{\mathrm{e}}\right)$, the F-ratio at a confidence level of $(1-\alpha)$ against DOF $=$ and error DOF $\left(f_{e}\right) ; V_{e}$, variance of error; $R$, sample size for confirmation experiment; $\mathrm{n}_{\mathrm{eff}}$, effective number of replications $=\mathrm{N} /$ $[1+$ total DOF in the estimation of mean]; $\mathrm{N}$, total number of results $=50$

Using the following values (table 6):

$$
V_{e}=0.6641
$$

Total degree of freedom in estimation of mean $=8$

$$
\begin{aligned}
& n_{\text {eff }}=8.33 \\
& F_{0.05}(1,8)=5.32
\end{aligned}
$$

The confidence interval $=2.19$; The $\mathrm{CI}$ of predicted impact strength at $95 \%$ confidence interval is $=11.8 \pm 2.19 \mathrm{~J}$

The optimum value of process parameters for the predicted range of impact strength are:

\section{Reinforcement: $4 \%$ \\ Particle size: $250 \mu$ \\ Aging time: $0.5 \mathrm{~h}$}

3.2c Confirmation experiments: On the basis of conclusions drawn based on Taguchi's method, the predicted results are verified. As the predicted optimum parameters of experiment number 1 of table 3 there has been no need to do confirmation experiments. The results of experiment number 1 are near to the predicted value.

3.2d Effect of selected parameters on impact strength: The effect on impact strength by affecting variables has been shown in figure 6. The impact strength shows a decreasing trend with increase in amount of reinforcement as in case with Ozden et al [26]. This effect may be due to the presence of hard reinforcement particles reduced toughness. With increase in particle size of the reinforcement, value of impact strength increases [26]. It may be due to larger particle size improves ductility by reducing the surface area of reinforcement. Also the larger size particles increases void space which results in improvement ability to allow more dislocation hence increasing sock absorbing capacity. This trend also visible from fracture surfaces shown in figure $5 \mathrm{c}$ and $\mathrm{f}$ of experiment no. 18 having impact strength $=8 \mathrm{~J}$, and experiment no. 21 having impact strength of $8.5 \mathrm{~J}$. Figure $5 \mathrm{f}$ shows more ductile zone than the figure $5 \mathrm{c}$ i.e., experiment number 21 has more ductile fracture area than experiment no. 18. Also, it can be observed from experiment number 21 and experiment number 18 that despite an increase in percentage reinforcement from 16 to $20 \%$ and aging time 24 $\mathrm{h}$ (which have a negative effect on impact strength), impact strength still increases. This shows that the effect of particle size has been more significant than percentage reinforcement and aging time. When the aging time of the fabricated composite increased it gives a negative effect 


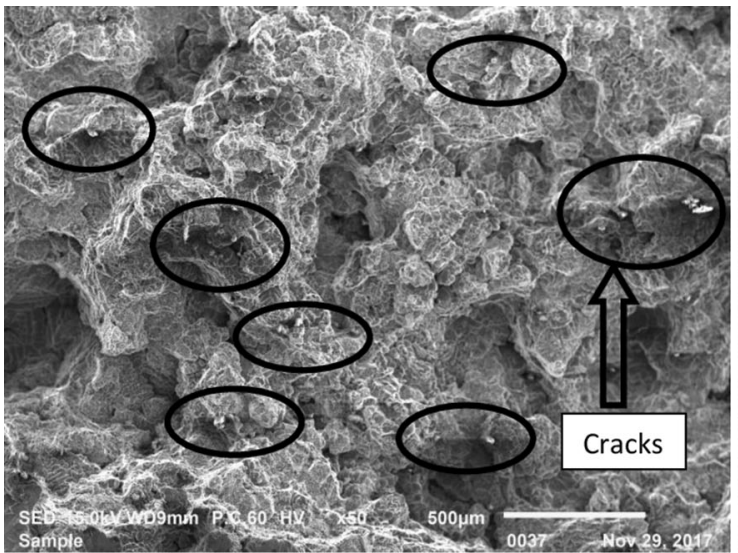

(a)

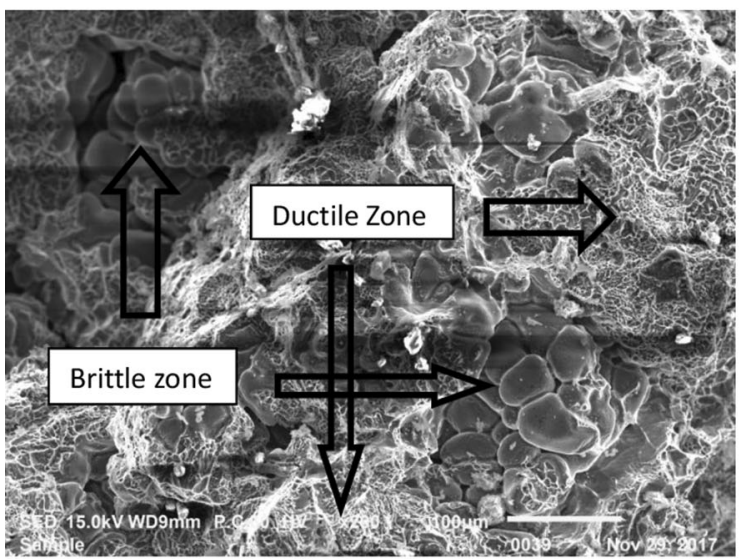

(c)

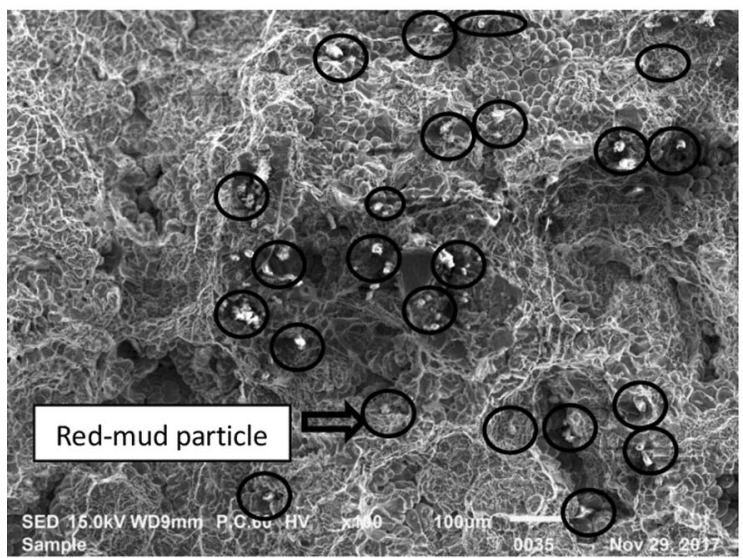

(e)

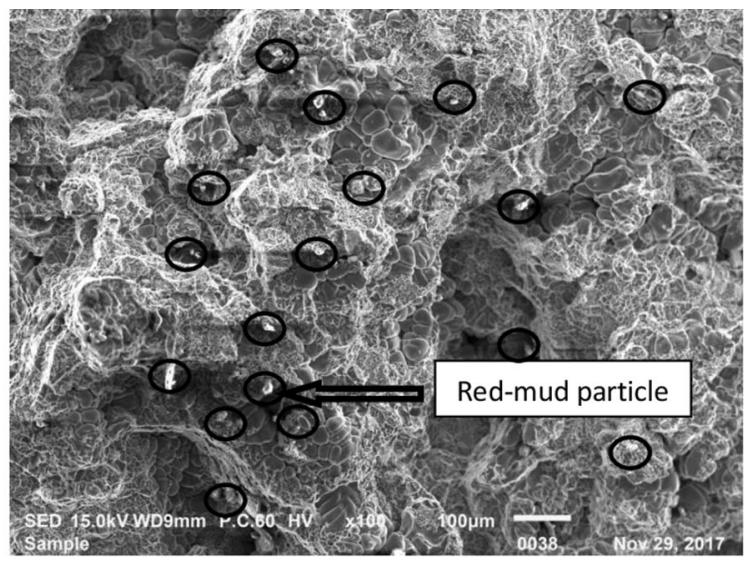

(b)

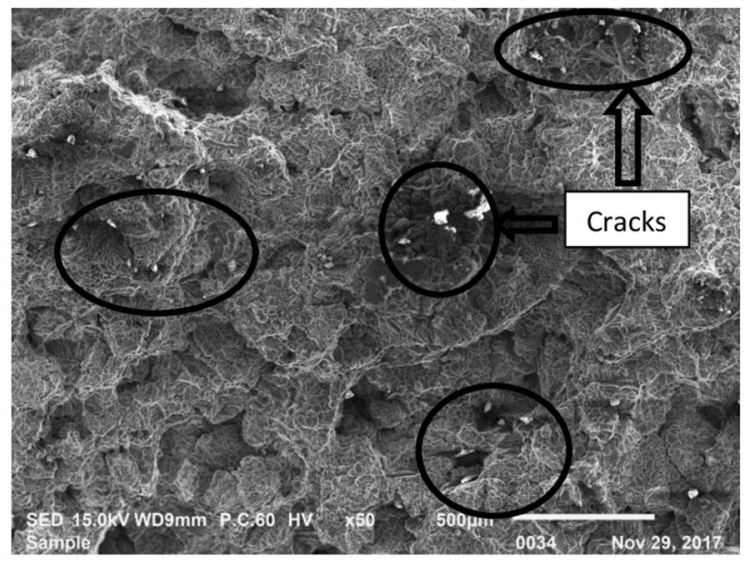

(d)

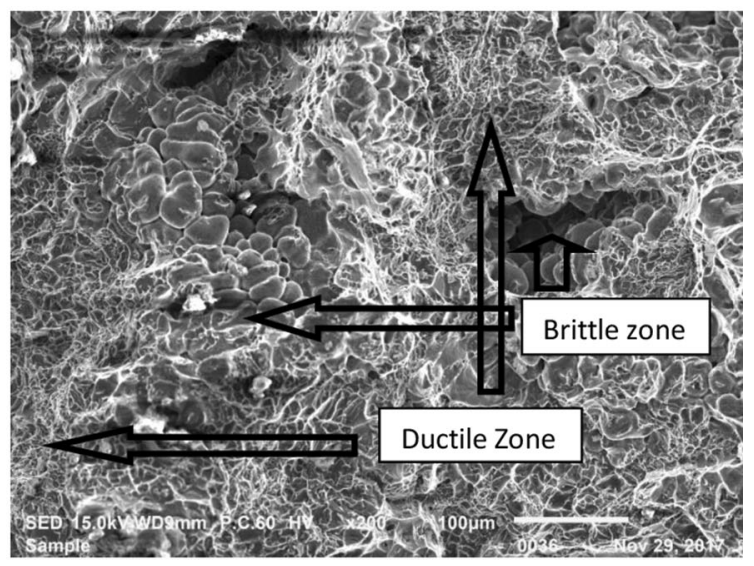

(f)

Figure 5. SEM image of fractured surface after impact testing at different heat treatment, percentage and particle size of reinforcement, and magnification. (a) Homogenized, 16\%, $149 \mu \mathrm{m}, \times 50$. (b) Homogenized, 16\%, $149 \mu \mathrm{m}, \times 100$. (c) Homogenized, $16 \%, 149 \mu \mathrm{m}$, $\times 200$. (d) Aged 24 h, 20\%, $250 \mu \mathrm{m}, \times 50$. (e) Aged 24 h, 20\%, $250 \mu \mathrm{m}, \times 100$. (f) Aged 24 h, $20 \%, 250 \mu \mathrm{m}, \times 200$. 
Table 3. Impact strength results with $\mathrm{S} / \mathrm{N}$ ratios

\begin{tabular}{|c|c|c|c|c|c|}
\hline Experiment no. & Percentage reinforcement (by wt) & Particle size $(\mu \mathrm{m})$ & Aging time (h) & Impact strength $(\mathrm{J})$ & $\mathrm{S} / \mathrm{N}$ ratio \\
\hline 1 & 4 & 250 & 0.5 & 14.0 & 22.9226 \\
\hline 2 & 4 & 177 & 6 & 7.00 & 16.9020 \\
\hline 3 & 4 & 149 & 12 & 7.25 & 17.2068 \\
\hline 4 & 4 & 74 & 18 & 6.00 & 15.5630 \\
\hline 5 & 4 & 125 & 24 & 5.50 & 14.8073 \\
\hline 6 & 8 & 250 & 6 & 10.50 & 20.4238 \\
\hline 7 & 8 & 177 & 12 & 7.50 & 17.5012 \\
\hline 8 & 8 & 149 & 18 & 6.75 & 16.5861 \\
\hline 9 & 8 & 74 & 24 & 6.25 & 15.9176 \\
\hline 10 & 8 & 125 & 0.5 & 6.50 & 16.2583 \\
\hline 11 & 12 & 250 & 12 & 10.00 & 20.0000 \\
\hline 12 & 12 & 177 & 18 & 7.25 & 17.2068 \\
\hline 13 & 12 & 149 & 24 & 6.00 & 15.5630 \\
\hline 14 & 12 & 74 & 0.5 & 6.50 & 16.2583 \\
\hline 15 & 12 & 125 & 6 & 7.00 & 16.9020 \\
\hline 16 & 16 & 250 & 18 & 10.0 & 20.0000 \\
\hline 17 & 16 & 177 & 24 & 7.00 & 16.9020 \\
\hline 18 & 16 & 149 & 0.5 & 8.00 & 18.0618 \\
\hline 19 & 16 & 74 & 6 & 5.50 & 14.8073 \\
\hline 20 & 16 & 125 & 12 & 6.00 & 15.5630 \\
\hline 21 & 20 & 250 & 24 & 8.50 & 18.5884 \\
\hline 22 & 20 & 177 & 0.5 & 8.00 & 18.0618 \\
\hline 23 & 20 & 149 & 6 & 7.50 & 17.5012 \\
\hline 24 & 20 & 74 & 12 & 5.00 & 13.9794 \\
\hline 25 & 20 & 125 & 18 & 5.50 & 14.8073 \\
\hline
\end{tabular}

Table 4. Response table for signal to noise ratios

\begin{tabular}{lccc}
\hline Level & Percentage reinforcement & Particle size & Aging time \\
\hline 1 & 17.48 & 15.31 & 18.31 \\
2 & 17.34 & 15.67 & 17.31 \\
3 & 17.19 & 16.98 & 16.85 \\
4 & 17.07 & 17.31 & 16.83 \\
5 & 16.59 & 20.39 & 16.36 \\
Delta & 0.89 & 5.08 & 1.96 \\
Rank & 3 & 1 & 2 \\
\hline
\end{tabular}

Table 5. Response table for means

\begin{tabular}{lccc}
\hline Level & Percentage reinforcement & Particle size & Aging time \\
\hline 1 & 7.95 & 5.85 & 8.60 \\
2 & 7.50 & 6.10 & 7.50 \\
3 & 7.35 & 7.10 & 7.15 \\
4 & 7.30 & 7.35 & 7.10 \\
5 & 6.90 & 10.6 & 6.65 \\
Delta & 1.05 & 4.75 & 1.95 \\
Rank & 3 & 1 & 2 \\
\hline
\end{tabular}

on impact strength [15]. This reduction in impact strength may be due to hardening of matrix because of aging. This increase in hardness reduces toughness that results in

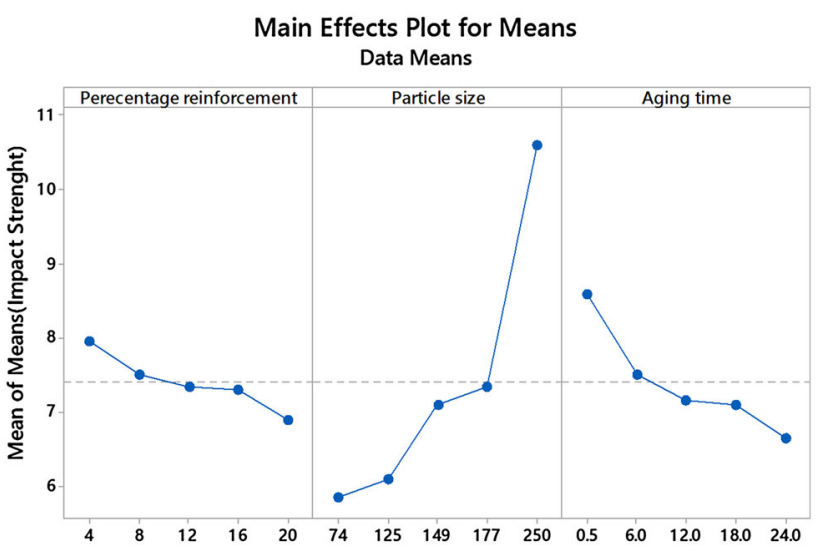

Figure 6. Mean values of impact strength.

reduction of impact strength. ANOVA analysis reports that the effect of particle size and aging time has been significant whereas percentage reinforcement does not have a significant effect. The significance of particle size has been highest and of percentage reinforcement has been least. 
Table 6. ANOVA analysis for impact strength

\begin{tabular}{lcrrrrr}
\hline Source & Degree of freedom & Sum of squares & Variance & F ratio & P value & Percentage contribution \\
\hline Percentage reinforcement & 4 & 2.335 & 0.5838 & 0.88 & 0.505 & 02.29 \\
Particle size & 4 & 80.661 & 20.1652 & 30.36 & 0.000 & 79.12 \\
Aging time & 4 & 10.981 & 2.7453 & 4.13 & 0.025 & 10.77 \\
Residual error & 12 & 7.970 & 0.6641 & & & 07.81 \\
Total & 24 & 101.947 & & & \\
\hline
\end{tabular}

\section{Conclusions}

On the basis of experimental work and analysis carried out, the following conclusions can be drawn.

1. Composite has been successfully casted by using stir casting. Fairly uniform distribution of red mud reinforcement has been observed by SEM micrographs.

2. Impact strength shows a decreasing trend with increase in percentage reinforcement, aging time and is increased with increase in particle size.

3. ANOVA analysis found that the effect of particle size $(79.12 \%)$ and aging time $(10.77 \%)$ are significant but the effect of percentage reinforcement $(2.29 \%)$ has not been found significant. Particle size has been influencing the impact strength mostly followed by aging time and percentage reinforcement.

4. Optimum value of impact strength $(11.8 \pm 2.19)$ has been predicted by using Taguchi technique and the same has been confirmed experimentally.

\section{Acknowledgements}

Authors are thankful to the Science and Engineering Research Board, New Delhi (India) for funding this research project through Fast Track Young Scientist Engineering Science Scheme vide their Letter No. SB/ FTP/ETA-148/2013, Dated: 31/10/2013.

\section{References}

[1] Jebeen Moses J, Dinaharan I and Joseph Sekher S 2016 Prediction of influence of process parameters on tensile strength of AA6061/TiC aluminum matrix composites produced using stir casting. Trans. Nonferrous Met. Soc. China 26: $1498-1511$

[2] Mahmoud T S, Mahmoud F H, Zakaria H M and Khalifa T A 2008 Effect of squeezing on porosity and wear behaviour of partially remelted A319/20 vol\% SiCp metal matrix composites. Proc. Inst. Mech. Eng. Part C J. Mech. Eng. Sci. 222: 295-303

[3] Rao R N, Das S and Krishna P V 2008 Experimental investigation on the influence of $\mathrm{SiC}$ particulate reinforcement in aluminium alloy composites. Proc. Inst. Mech. Eng. Part J J. Eng. Tribol. 222: 1-6
[4] Ahmadi I and Aghdam M M 2010 Analysis of micro-stresses in the $\mathrm{SiC} / \mathrm{Ti}$ metal matrix composite using a truly local meshless method. Proc. Inst. Mech. Eng. Part C J. Mech. Eng. Sci. 224: 1567-1577

[5] Rao R N and Murthy K M 2010 A mathematical model to evaluate wear depth of an aluminium alloy reinforced with a silicon carbide particle composite using finite element analysis. Proc. Inst. Mech. Eng. Part L J. Mater. Des. Appl. 224: 133-138

[6] Gomez L, Busquets-Mataix D, Amigo V and Salvador M D 2009 Analysis of boron carbide aluminum matrix composites. J. Compos. Mater. 43: 987-995

[7] Mazahery Ali and Ostadshabani Mohsen 2011 Investigation on mechanical properties of nano- $\mathrm{Al}_{2} \mathrm{O}_{3}$-reinforced aluminium matrix composites. J. Compos. Mater. 45: 2579-2586

[8] Guo E J, Yue H Y, Fei W D and Wang L P 2012 Tensile properties of $\mathrm{ZnO}$ - and $\mathrm{ZnAl}_{2} \mathrm{O}_{4}$-coated aluminum borate whiskers reinforced aluminium composites at elevated temperatures. J. Compos. Mater. 46: 1475-1481

[9] Li S, Sua Y, Zhu X, Jina H, Ouyanga Q and Zhanga D 2016 Enhanced mechanical behavior and fabrication of silicon carbide particles covered by in-situ carbon nanotube reinforced 6061 aluminum matrix composites. Mater. Des. 107: $130-138$

[10] Wang S, Wang Y, Li C, Chi Q and Fei Z 2007 The dry sliding wear behavior of interpenetrating titanium trialuminide/aluminium composites. Appl. Compos. Mater. 14: 129-144

[11] Uthayakumar M, Aravindan S and Rajkumar K 2013 Wear performance of Al-SiC-B4C hybrid composites under dry sliding conditions. Mater. Des. 47: 456-464

[12] Sahraeinejad S, Izadi H, Haghshenas $M$ and Gerlich A P 2015 Fabrication of metal matrix composites by friction stir processing with different Particles and processing parameters. Mater. Sci. Eng. A. 626: 505-513

[13] Singh J and Chauhan A 2016 Characterization of hybrid aluminum matrix composites for advanced applications-a review. J. Mater. Res. Technol. 5(2): 159-169

[14] Alaneme K K, Adewale T M and Olubambi P A 2014 Corrosion and wear behaviour of $\mathrm{Al}-\mathrm{Mg}-\mathrm{Si}$ alloy matrix hybrid composites reinforced with rice husk ash and silicon carbide. J. Mater. Res. Technol. 3(1): 9-16

[15] Ibrahim M F, Ammar H R, Alkahtani S A and Samuel F H 2016 Metallographic investigation of tensile- and impact-tested aluminum composites. J. Compos. Mater. 50(20): 2793-2805

[16] Mahmoud T S 2008 Tribological behaviour of A390/Grp metal-matrix composites fabricated using a combination of rheocasting and squeeze casting techniques. J. Mech. Eng. Sci. 222: 257-265 
[17] Mahesh V P, Nair P S, Rajan T P D, Pai B C and Hubli R C 2011 Processing of surface-treated boron carbide-reinforced aluminum matrix composites by liquid-metal stir-casting technique. J. Compos. Mater. 45(23): 2371-2378

[18] Rao V R, Ramanaiah N and Sarcar M M M 2016 Mechanical and tribological properties of AA7075-TiC metal matrix composites under heat treated (T6) and cast conditions. $J$. Mater. Res. Technol. 5(4): 377-383

[19] Mistry J M and Gohil P P 2017 An overview of diversified reinforcement on aluminum metal matrix composites: tribological aspects. Proc. Inst. Mech. Eng. Part J J. Eng. Tribol. 231: $1-23$

[20] Sharma P, Khandujaa D and Sharma S 2016 Dry sliding wear investigation of $\mathrm{Al} 6082 / \mathrm{Gr}$ metal matrix composites by response surface methodology. J. Mater. Res. Technol. 5: 29-36

[21] Bodunrin M O, Alaneme K K and Chown L H 2015 Aluminium matrix hybrid composites: a review of reinforcement philosophies; mechanical, corrosion and tribological characteristics. J. Mater. Res. Technol. 4: 434-445

[22] García-Romero A M, Egizabal P and Irisarri A M 2010 Fracture and fatigue behaviour of aluminium matrix composite automotive pistons. Appl. Compos. Mater. 17: 15-30

[23] Prakash K S, Kanagaraj A and Gopal P M 2015 Dry sliding wear characterization of Al 6061/rock dust composite. Trans. Nonferrous Met. Soc. China. 25: 3893-3903

[24] Dharmalingam S, Subramanian R and Kok M 2014 Optimization of abrasive wear performance in aluminium hybrid metal matrix composites using Taguchi-grey relational analysis. Proc. Inst. Mech. Eng. Part J J. Eng. Tribo. 227: 749-760

[25] Ross P J 1996 Taguchi Techniques for Quality Engineering. 2nd edn. New York: McGraw-Hill Publishing Co.

[26] Ozden S, Ekici R and Nair F 2007 Investigation of impact behaviour of aluminium based $\mathrm{SiC}$ particle reinforced metalmatrix composites. Compos. Part A. 38: 484-494 